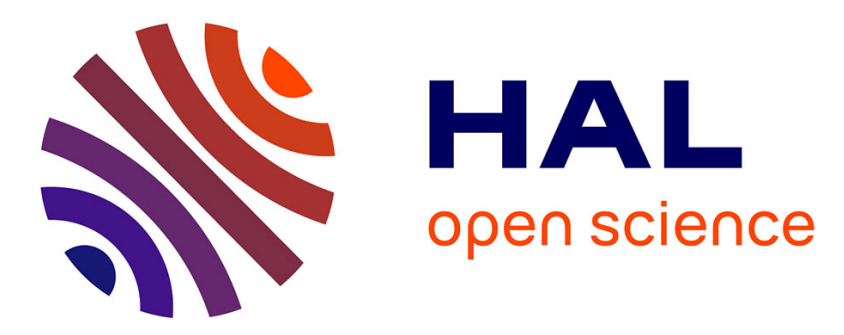

\title{
EXPLOITING SCM AS SOURCE OF COMPETITIVE ADVANTAGE: THE IMPORTANCE OF COOPERATIVE GOALS REVISITED
}

François Fulconis, Gilles Paché

\section{- To cite this version:}

François Fulconis, Gilles Paché. EXPLOITING SCM AS SOURCE OF COMPETITIVE ADVANTAGE: THE IMPORTANCE OF COOPERATIVE GOALS REVISITED. Competitiveness Review, 2005, Vol. 15 ( $\left.\mathrm{N}^{\circ} 2\right)$, pp. 92-100. hal-02304245

HAL Id: hal-02304245

https://hal-amu.archives-ouvertes.fr/hal-02304245

Submitted on 3 Oct 2019

HAL is a multi-disciplinary open access archive for the deposit and dissemination of scientific research documents, whether they are published or not. The documents may come from teaching and research institutions in France or abroad, or from public or private research centers.
L'archive ouverte pluridisciplinaire HAL, est destinée au dépôt et à la diffusion de documents scientifiques de niveau recherche, publiés ou non, émanant des établissements d'enseignement et de recherche français ou étrangers, des laboratoires publics ou privés. 


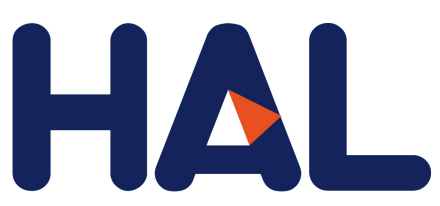

archives-ouvertes

\section{EXPLOITING SCM AS SOURCE OF COMPETITIVE ADVANTAGE: THE IMPORTANCE OF COOPERATIVE GOALS REVISITED}

François Fulconis, Gilles Paché

\section{- To cite this version:}

François Fulconis, Gilles Paché. EXPLOITING SCM AS SOURCE OF COMPETITIVE ADVANTAGE: THE IMPORTANCE OF COOPERATIVE GOALS REVISITED. Competitiveness Review, 2005, Vol. 15 ( $\left.\mathrm{N}^{\circ} 2\right)$, pp. 92-100. hal-02304245

HAL Id: hal-02304245

https://hal-amu.archives-ouvertes.fr/hal-02304245

Submitted on 3 Oct 2019

HAL is a multi-disciplinary open access archive for the deposit and dissemination of scientific research documents, whether they are published or not. The documents may come from teaching and research institutions in France or abroad, or from public or private research centers.
L'archive ouverte pluridisciplinaire HAL, est destinée au dépôt et à la diffusion de documents scientifiques de niveau recherche, publiés ou non, émanant des établissements d'enseignement et de recherche français ou étrangers, des laboratoires publics ou privés. 


\section{EXPLOITING SCM AS SOURCE OF COMPETITIVE ADVANTAGE: THE IMPORTANCE OF COOPERATIVE GOALS REVISITED}

\author{
by François Fulconis and Gilles Paché
}

\section{EXECUTIVE SUMMARY}

The majority of studies on supply chain management (SCM) emphasize the importance of cooperative relationships for improving the integration of business processes into a supply chain. It seems accepted that SCM will be a source of competitive advantage if, and only if, firms that participate in it formalize a strategic partnership between each other beforehand. This article questions whether this really is the case, given that the corporate cultures currently in place are largely founded on a tradition of adversarial relationships, the creation of large groups and the development of vertical concentrations. SCM could, in contrast, in such a case be the catalyst for powerful future strategic partnerships that could gently break arm'slength competition.

\section{INTRODUCTION}

The mid and late 1990s saw a veritable explosion in academic research conducted on the subject of supply chain management (SCM). It is true that an increasing number of manufacturing and retailing firms make decisions whose aim is to maximize the efficiency of the supply chains in which they are involved. For example, in a similar way to the famous case played out by Wal-Mart and Procter \& Gamble, it is now common practice in France for convenience goods manufacturers and large retailers to work closely together to reduce stock-outs in stores by means of improved coordination of their logistical activities (des Garets, 2000).

As a result, it is now evident that academics specializing in studies of strategic management have become greatly interested in SCM. For them, SCM effectively seems to be a very interesting illustration of the alliances and strategic partnerships that have developed enormously in Western economies in the last twenty years. The idea that is defended in many works is that collaboration between firms, aimed at improving supply chain operations, necessarily requires the existence of cooperative goals and therefore that a strategic partnership is required before an SCM approach can be implemented. More precisely, SCM is only the operational logistical dimension of an overall strategic partnership that has previously been built by two or more firms.

The aim of this paper is to attempt to reverse this reasoning by arguing whether the progressive implementation of an SCM could not, in contrast, be the first essential step in the implementation of a strategic partnership. This would undoubtedly surprise many North American practitioners who envisage SCM as being the result of a voluntary cooperative approach involving several firms who have become committed to work together over a long period to achieve a shared project.

In Europe, and more particularly in France, the cultural context is completely different and undoubtedly justifies such "reverse thinking." Here, the business tradition has been founded on adversarial relationships, the creation of large groups, the development of vertical concentrations and often very fierce competition in the distribution channels (Manzano-Mannarelli, 2000). From this point of view, an SCM approach could allow firms to gradually introduce more effective logistical procedures. In this way they would learn to work together and discover the positive effects of better coordination. By gaining a competitive advantage, they would be all the more encouraged to enter a sustainable true strategic partnership.

We wish to underline the pertinence of a culturalist approach to SCM and to point out that even in a "no trust" context, one of the major characteristics of European Latin culture, it is possible to consider a progressive implementation of collaborative practices, but using highly specific means. In order to better understand the various stakes, it will be necessary beforehand to describe the key elements of a SCM philosophy according to the academic literature, at operational and strategic level.

\section{AN EVOLUTIONARY APPROACH}

As a first rough estimate, even if this vision is sometimes disputed, a supply chain corresponds to a set of operations supporting logistical activities of procurement of materials in a network of first-tier and second-tier suppliers, of transformation of these materials into semi-finished or finished goods, then of their physical distribution to customers. The basic idea is that these activities and operations must be perfectly synchronized within the framework of SCM, so that customers can benefit from the best possible service quality at the lowest cost: "the entire chain is 
viewed as one process and the goal is to eliminate any inefficiencies or redundancies across the chain. In this way waste is eliminated and the entire chain becomes more flexible and responsive to customer needs" (Vokurka et al., 2002, p. 16).

Drawing from his professional experience, Stevens (1989) suggested the existence of four steps leading to the emergence of genuine SCM. Step 1 is distinguished by complete functional independence in so far as each function operates quite separately from all others, protected by "bricks" (stocks) allowing differences between their operating rhythms. In step 2, manufacturing firms recognize the urgent need for a minimum coordination between related functions, e.g. marketing and physical distribution, so as to eliminate a number of malfunctions. Next comes step 3 to increase the coordination effort by implementing the comprehensive planning of internal flows from downstream to upstream, leading to step 4 when supply chain members finally become aware that they are merely part of a whole.

The interest of this evolutionary approach is to highlight the fact that SCM refers to a succession of trade-offs (Lambert et al., 1998). Trade-offs occur within a firm (e.g. between purchasing and materials management, materials management and production, etc.), but also between firms belonging to the same supply chain (e.g. between purchasing and first-tier suppliers, marketing \& sales and customers, etc.). The objective is to find overall solutions, which through an intra and inter-organizational collaboration, will avoid a waste of resources and increase the profitability of supply chain members. An interesting case is that of convenience goods manufacturers, where large retailers and TPL service providers work together to create the packaging of a new product to reduce logistical costs, from factories to store shelves.

For most observers, the supply chain therefore appears to be the most pertinent level for analyzing the competitive environment. Competition between supply chains is based on minimizing the physical costs related to supply, production, transportation and inventory storage, but with great agility that relies on short-term order servicing. This double requirement signifies, not only the systematic reduction of the total stock of materials, of WIP and finished goods in each supply chain, but also a quick improvement in response times (lead times). Overall, the most efficient supply chain at any given time will be the one that is capable of integrating the lean and agile logistics paradigms in a "leagility" strategy (Naylor et al., 1999).

\section{INTEGRATION OF BUSINESS PROCESSES}

The trade press provides numerous examples of management tools whose purpose is to facilitate flow coordination. Most are based on interorganizational information systems (IOS) which are expected to make the supply chain more reactive. But this is a very narrow view of SCM which does not take into account its three complementary levels: the supply chain structure level, the business processes level and the management components level: "the supply chain network structure consists of the member firms and the links between these firms. Business processes are the activities that produce a specific output of value to the customer. The management components are the managerial variables by which the business processes are integrated and managed across the supply chain" (Lambert and Cooper, 2000, p. 69). It is easy to imagine how difficult it is to implement an effective SCM. SCM relies both on the control of physical and technical factors, and on managerial and behavioral components, particularly supply chain members supporting a kind of "meta-decision" which unavoidably reduces their freedom in monitoring logistical activities.

The integration of business processes is a critical area that some academic works have examined, among others the already dated but still relevant contribution of Scott and Westbrook (1991). The authors understood that the integration of business processes would have to be progressive to overcome the major barriers. It is first necessary to establish a sort of classification of vertical and horizontal lines within the supply chain, with measurement tools in terms of response time for each key step (in production, physical distribution, etc.). This makes it possible to model flows of products, and also importantly to identify possibilities for improvement. Then, exchange relationships within the supply chain, and more precisely firms managing any given part of them must be analyzed. The expected result is finally to provide the means of increasing the efficiency of the supply chain at each step, still bearing in mind the overall solutions previously mentioned.

An effective coordination of the supply chain cannot be considered from technical and technological dimensions only, as once was believed in works promoting process technology, product design, the implementation of EDI and electronic marketplaces, the development of ECR-EWR, etc. These are undoubtedly facilitators, but they are not capable on their own of leading to an integration of business processes. Those who think they are probably have conventional thinking implying that logistical 
techniques and technologies will naturally lead to cooperative strategies between supply chain members. But the integration of business processes also depends on the nature of power regimes. Fierce fighting for value appropriation thus goes against the integration of business processes in some cases, if one of the members does not find any direct interest in it (Cox et al., 2001).

Drawing from research on distribution channels, it seems essential to introduce oftenneglected behavioral dimensions in the analysis of SCM. After all, even if the interest of a manufacturing or a retailing firm first lies in trying to integrate business processes, does not that firm finally consider its own profitability, including the use of coercive power? This simple reality is unfortunately rarely mentioned in many publications on SCM. At the end of their extensive literature review, Croom et al. (2000) reach the conclusion that the most significant academic works study the management of assets and information systems, and neglect the aspects linked to managerial decisions. Moreover, the authors note an almost complete lack of theoretical reflection on the strategic stakes of SCM, in a mostly empirical and descriptive literature. But there lies the fundamental issue in understanding future developments in SCM.

\section{STRATEGIC DIMENSIONS}

Academic publications on the role of logistics in corporate strategy have been developing for some years, often in reference to existing models (logistics as a source of competitive advantage, as a core competence, as a critical asset, etc.). In this emerging literature, Cavinato's (1999) contribution on the possible parallel between the development phases of strategic management and those of logistics and SCM may be mentioned. Our paper fills out a complementary area by studying the relationship between SCM and strategic partnerships, with the following question: is SCM the result of or the origin of strategic partnerships? A preliminary clarification of terminology is required before an answer can be provided.

To sum up, strategic partnerships are similar to alliances whose purpose is to develop meshing operations, R \& D, product launching, etc., between partners. Their success requires the existence of a shared project closely associating all partners in the long term. This subject, particularly significant for strategic management, has given birth to an abundant literature since the 1990s. The majority current opinion is that when two or more firms develop cooperative logistics relationships, for example by implementing a VMI or a CPFR program, it is because they have first implemented a strategic partnership whose existence is partly based on a coordinated management of flows.

According to Hauguel and Viardot (2001), the emergence of an effective SCM depends on a strategic intent and on preliminary action at three levels: (1) the implementation of balanced exchange relationships between partners; (2) a complete transparency of information between them; and (3) rigorous tools of performance monitoring (for a fair share of the partnership's benefits and burdens). It should be noted that the most recent work on the use of a balanced scorecard to measure SCM performance is similar in its reasoning (Brewer and Speh, 2000). In other words, it is useless to try to apply cooperative logistics relationships to a strategic arm's-length relationship style: this is bound to fail.

The desire to cooperate at a strategic level naturally leads to better supply chain coordination. In fact, it would appear difficult for supply chain members to want to quit adversarial relationships while maintaining totally compartmentalized logistical organizations that result in much wastage (e.g. large number of stocking points, maintaining a speculative inventory policy, and badly organized transport from factories to warehouses). Interaction between SCM and corporate strategy may be viewed as a sequential approach, preceded by the definition of cooperative goals shared by several firms (alliances to penetrate a new market, design a new product, etc.). These firms develop a strategic partnership, which requires concrete actions at supply chain level to become operational. If SCM provides satisfying results in terms of logistical costs, service quality and reactivity, conditions are then created for the continuation of the strategic partnership (Burnes and New, 1997).

\section{FROM SCM TO STRATEGIC PARTNERSHIPS}

But it would be naive to believe that cooperative goals automatically operate at all the functional and operational levels of an alliance. Partners will identify which parts of their value chain require close collaboration to generally become more efficient, even if this means establishing competition in another part of the value chain where competition may seem desirable to improve efficiency. Hence an ambiguous admission: "whilst decisions regarding whom and whom not to enter into a relationship with are reached more and more at the strategic level, their success or failure will be worked out at the operational level. It is at this level, through the day-today interaction between the two organizations, that 
trust, cooperation and openness can develop" (Burnes and New, 1997, p. 16). In a word, is not the operational level the ideal entry point to build a possible strategic partnership?

All depends on the way SCM is considered and analyzed: is it, to recall the comprehensive review of Mentzer et al. (2001), a management philosophy, the implementation of a management philosophy or a set of management processes? SCM is obviously all of these, even if in the end it can be considered as an integrative approach forcing supply chain members to think together about technological and managerial innovations to create customer value. Implementing this approach requires fulfilling two conditions: (1) a long-term work, partly based on organizational learning in the monitoring of logistical activities, and which will lead partners in the step-by-step building and maintenance of long-term relationships; (2) a collective decision-making process associating all partners in the implementation of agile supply chains, leading to an equitable share of the value-added (Paché, 2003).

Associating SCM exclusively with strategic partnerships would be a mistake in interpretation. In today's business world, inter-firm relationships develop along a continuum ranging from an arm'slength relationship style to a full vertical integration, and each relationship style has its own SCM methods in the areas of information exchange, planning and operating controls (Cooper and Gardner, 1993). But it is undeniable that starting from day-to-day interactions allows partners to get to know each other better, to build a "logistical common knowledge" and to try a new type of exchange relationship which may lead them to a strategic partnership.

The example of large French retailers and their own label producers is an interesting case since the continuous improvement of supply chain operations has now resulted in a shared development policy for new products and retail marketing. Peck and Jüttner (2000), analyzing the UK brewing industry, reached a very similar conclusion: the implementation of collective strategies implies a more or less intense logistical prerequisite, particularly when automatic replenishment systems are considered to be a source of competitive advantage. The supply chain members first realize that an effective CPFR requires a regular and reliable share of information, and later become aware of the advantages of working together on sales forecasting and further upstream on developing coordinated marketing projects.

The major advantage of the supply chain concept is to make the firms closely interacting in the process of creating value aware of the existence of potential sources of inefficiency at interfaces, and of the urgency of a strategic determination to eliminate them. This will very likely lead to the design of new logistical combinations, whose philosophy would be based on a "theory of optimization." This "theory of optimization" in its turn should necessarily lead supply chain members to look for possible ways of increasing value in a concerted manner, by reassessing inter-organizational relationships in all their dimensions. From this point of view, the SCM approach could be the indispensable preliminary step to the emergence of network organizations, and not the reverse.

\section{SCM AND THE CHALLENGE OF COMPETITIVENESS IN A LATIN CULTURE CONTEXT}

When the current behaviors of manufacturing or retailing firms are examined, it is evident that many of them are trying to optimize their inbound logistics. A frequent consequence of this is a sort of leveling down of logistical exchange relationships with the different trading partners so as to improve the operation of supply chains, and ultimately increase customers' satisfaction. The SCM approach is in keeping with this development, although it is uncertain whether the existence of a strategic partnership is an indispensable prerequisite.

Looking at academic works, including the most recent ones, it remains difficult to form an opinion. But, assuming that the implementation of SCM is a source of competitiveness, this paper will formulate three conclusions representing as many perspectives for further research to clarify the link between SCM and strategic intent. Each conclusion corresponds to a case taken from the operation of food supply chains in France. These different examples show how an SCM approach can contribute to the progressive disappearance of adversarial relationships in a country having a Latin culture with a predominance of mistrust, and sometimes the desire to deceive commercial partners to improve one's own competitive position.

\section{A strategic intent governs the implementation of SCM}

Although it is difficult to answer the question: "is SCM the result of or the origin of a strategic partnership?" it is certain that in any firm, a strategic intent or desire governs the implementation of the SCM approach. It corresponds to a declared ambition, that of monitoring logistical activities differently to optimize the supply chain (Poirier and Reiter, 1996). The strategic intent is based on a cooperative purpose aiming at a long-term 
involvement of the firm's various components including the organizational structure- to obtain the capacities required for the optimal monitoring of flows (goods and information).

The idea that dominated for a long time, according to which logistics remains deeply -and solely- related to an operational approach that relies on a philosophy of optimization and exploiting the firm's capacities, should therefore be superseded. The academic literature also emphasizes the emergence of two major trends since the mid 1990s that go in this direction: (1) the search for more suitable measurement methods for correctly assessing logistical performance (LaLonde and Pohlen, 1996; Seuring, 2002); (2) the use of logistics as a means for the firm to lastingly change the rules of the competition game to its own advantage (Fulconis, 1999; Lebraty, 2000).

In addition to their ability to adapt to environmental conditions, logistics has a resolutely proactive character on which is based the strategic intent to govern the implementation of the SCM approach (see Case No. 1 below). This evolutionary trend leads us to a second conclusion according to which, at managerial decision level, the strategic intent requires a transverse vision to the firm's operations, and involves both its business processes and behavioral components.

Case No. 1. Délifruits, a 200-employee SME specializing in fruit juice, iced tea and flavored water in PET bottles, in twenty years became one of the market leaders in France. As early as the end of the 1990s, its CEO understood that it was absolutely essential to improve supply reliability for retailers' warehouses, one of the firm's weak points. He thought it was the only way to concretize his strategic intent, i.e. an entrenchment in durable relationships with his main clients. Délifruits' CEO thus succeeded in convincing several large French retailers that improving logistics required a daily transmission of data on sales of products in outlets. At first reluctant, the large retailers finally accepted when they discovered that the number of stock-outs decreased by 20 per cent in six months.

Délifruits and its main client went even further and together developed balanced scorecard to obtain a quarterly monitoring of their joint logistical performances, and take corrective measures in the event of deteriorating results. In spite of its modest size, Délifruits gradually managed to become a favored supplier of the European food retailing industry, reputed for its fierceness in commercial negotiations. Having obtained the ISO 14001 certification (environmental certification) and the OHSAS certification (food safety certification), the firm now manufactures a large number of products for multinational corporations like Coca-Cola and Décathlon.

\section{SCM requires and encourage functional integration}

The cooperative purpose will necessarily be found at operational level, at the core of the firm's operating capacities. It is in fact the essential support for optimizing the supply chain and implementing JIT strategies (Bramel and Simchi-Levi, 1997; Tayur et al., 1998). In the process of reengineering the logistical system, the term "functional integration of logistics" is now in vogue. Managers must pay attention to answering the following questions: how are logistics taken into account by the firm's other functions and how do logistics take into account their objectives and constraints? What tools, particularly in terms of information systems, would help functional integration and what are its organizational implications?

Confronted with these questions, the SCM approach encourages supply chain members to prefer a transverse vision and to consider logistics as an integrative technology of flow control within companies, with cross-functional and cross-divisional collaboration, and collaboration between companies, from suppliers' suppliers to customers' customers (Fabbe-Costes and Roussat, 2002). As an example, we take the case of the French food company Solinest which is involved in the biscuits and candies sector as sole distributor of several major brands (Freedent, Tetley, Fisherman's Friend, etc.) to large retailers and wholesalers. Since 1997, Solinest has developed a new logistical organization including tracking and integral tracing of products, stock inventory optimization and the implementation of a VMI program.

Again, we come across the idea that SCM as a management philosophy occurs in a sequential process: first, improvement of internal interfaces between logistics and other functions, then improvement of external interfaces between the supply chain members. This explains that firms belonging to the Latin culture have fallen behind in the matter of SCM. The managers of each major function (marketing, purchasing, finance, etc.) always had great difficulties in accepting a transverse and global vision of the firm, and preferred promoting their own function's local performance. But Case No. 2 shows that a change of mentality is under way.

Case No. 2. Intermarché, one of the four major food retailers in France, is an example of functional integration offered by an SCM approach. Until the end of the 1980s, the firm left its purchasers totally free to conduct a policy of speculative inventories, consisting of buying very large quantities 
of products to benefit from suppliers' attractive prices with discounts of up to $30 \%$ off the catalog price. Thus Intermarché often found itself with quantities of biscuits or chocolate covering the needs of outlets for six to nine months!

At the end of the 1990s, Intermarche's supply chain manager brought to the CEO's attention the huge logistical costs resulting from speculative inventories, which were almost as high as the gains obtained during purchasing. He also pointed out that warehousing food products over a long period was highly detrimental to their taste and quality, and gave the image of a large retailer with little respect for the freshness of its product assortment. The CEO recognized the pertinence of this analysis and decided to abandon the policy of speculative inventories. Warehouses now have stocks for a few days, just sufficient to meet the outlets' ordinary needs. Supply procedures have been completely reviewed and are the result of a cross-functional collaboration involving the buying, supply chain and marketing managers.

More generally, it should be noted that although SCM introduces some agility in the supply chain's members' ability to transform themselves, it is not necessary to reconsider the whole organization. According to Cap Gemini's International Supply Chain Manager, speaking in January 1999 at a Roundtable on SCM as a competitive weapon (Paris), the issue is not to apply perfectionism to all processes, but to concentrate on the 20 per cent which creates enough value-added to dominate the market.

\section{SCM determines the emergence of successful strategic partnerships}

Finally, only a strategic intent and a cooperative purpose inside each firm, both at strategic and operational levels, allow the implementation of an effective SCM approach. With such an approach, supply chain members can mobilize skills upstream and downstream of their own activity, while strengthening their reactivity. In an ongoing process of "inter-organizational integration," firms will therefore become involved in more or less advanced logistical collaboration with their supplier(s) and/or their client(s).

According to Dornier and Fender (2001), three general types of logistical collaboration can be distinguished between a manufacturer and a retailer (see Fig. 1): (1) logistical and operational collaboration, whose aim is both to eliminate the costs of logistical malfunctions by complying with contract conditions and increasing the productivity of the operations; (2) logistical and commercial collaboration, whose aim is not only to minimize the sum of operational costs, but also to integrate the commercial component (increase sales, turnover and margins by the most suitable organizations and logistical systems); and (3) logistical and marketing collaboration, whose aim is to increase the utility provided to the consumer by adapting the product using a shared marketing conception and campaign (long-term relationships, shared investments and benefits).

Therefore some firms, more aware than others of the positive effects of an improved logistical coordination, decided to go further and to completely reformulate their supply chain from a shared project, thus creating real network organizations (Jarillo, 1993; Miles and Snow, 1995). Is this not the key to the success of strategic partnerships formed with their suppliers and/or their clients by companies like McKesson, Benetton, Nike, Micro Compact Car (MCC) and more recently, Dell or Amazon? But Case No. 3 shows that one should not jump to generalizations too quickly.

Case No. 3. The way the Carrefour group the second largest retailer in the world after WalMart- operates is an excellent illustration of the "small steps policy" leading from a logistical and operational collaboration to a logistical and marketing collaboration in a Latin culture context. The Carrefour Europe supply chain manager, speaking in May 2003 at a Roundtable on the monitoring of global supply chains (Aix-en-Provence), explained how, for the last ten years, his firm had decided to progress in gradual stages with its suppliers.

As a first stage, simple coordination tools were implemented, particularly in EDI. As a second stage, thanks to an effect of organizational learning, the firm involved some of its suppliers in increasingly sophisticated collaborative practices: first a VMI, then joint management of promotions and finally a CPFR. But as stated in the Carrefour Europe supply chain manager's conclusion, only a reduced number of suppliers may hope to reach the more refined levels of logistical and marketing collaboration. These are suppliers for whom implementing a strategic partnership offers a significant financial and marketing interest for the Carrefour group, in conjunction with, for example, the innovative nature of proposed products and/or specific skills in advertising or merchandising. 
FIGURE 1

Evolution of the manufacturer-retailer interfaces

(adapted from Dornier and Fender [2001], p. 388)

\section{Manufacturers}

$\begin{array}{cclc}\text { Marketing } & \text { Sales } & \begin{array}{c}\text { Physical distribution } \\ \text { Manufacturers' } \\ \text { warehouses } \\ \text { Logistical and operational } \\ \text { collaboration }\end{array} & \begin{array}{c}\text { Physical distribution } \\ \text { Retailers' warehouses }\end{array} \\ \stackrel{\text { Logistical and commercial collaboration }}{\longrightarrow}\end{array} \longrightarrow$

\section{CONCLUSIONS AND MANAGERIAL IMPLICATIONS}

The outcome of our study is that it now appears that SCM is of the highest priority interest for the top management of firms searching for competitiveness. Based on changes in logistics and the use of many recent conceptual and technical tools such as EDI, VMI and CPFR, SCM provides a series of solutions for combining profitability and consumer service. But it also contains a strategic dimension that calls into question the European business culture that has for a long time been dominated by a spirit of competition between firms rather than cooperation.

Nevertheless, in this article we have wanted to emphasize that in Latin Europe it seems more logical and promising to develop an SCM approach step-by-step within and between firms, rather than to engage immediately in a choice of inter-firm cooperation. Although SCM often appears to some observers to be a series of tools favoring corporate reengineering by means of a transverse vision, it constitutes none-the-less a structured approach that also plays a dynamic role of inter-organizational integration founded on powerful logistical collaboration. It is only after adopting SCM, but definitely not beforehand, that the importance of cooperative goals and the implementation of a real strategic partnership makes sense by strengthening the competitiveness of inter-organizational relationships.

In conclusion, it is possible to identify an important managerial recommendation. If a supplier and a manufacturer, or a manufacturer and a large retailer, are capable of quantifying as exactly as possible the impacts of a better logistical coordination between them (stage 1), they will be able far more easily to adopt joint strategies of design, manufacturing and marketing of new innovative products (stage 2). Of course, some observers will note that there is nothing new here in relation with the trade marketing philosophy, ever present in agri-food chains. But we think that the advocates of trade marketing's mistake is to suggest that there must be simultaneous implementation of collaborative practices both in a logistical perspective and a marketing perspective.

To succeed in a "no trust" context, collaborative practices must on the contrary follow a sequential order. In our opinion, it is better to start with logistical dimensions, easier to measure in terms of performance, than to deal with marketing dimensions, which are often the subject of confrontation between trading partners for value appropriation. According to Vokurka et al. (2002, p. 16), "in essence, the supply chain must pursue profits and strategic business goals in a similar fashion to that of a single company." For the time being, we are obliged to recognize that this vision seems more like an ideal to be attained than an emergent reality in Latin Europe. 


\section{REFERENCES}

Bramel, Julien and David Simchi-Levi (1997). The logic of logistics. New York (NY): SpringerVerlag.

Brewer, Peter C. and Thomas W. Speh (2000). Using the balanced scorecard to measure supply chain performance. Journal of Business Logistics, 21(1), 75-93.

Burnes, Bernard and Steve New (1997). Collaboration in customer-supplier relationships: strategy, operations and the function of rhetoric. International Journal of Purchasing and Materials Management, 33(4), 10-17.

Cavinato, Joseph L. (1999). A general methodology for determining a fit between supply chain logistics and five stages of strategic management. International Journal of Physical Distribution \& Logistics Management, 29(3), 162-180.

Cooper, Martha C. and John T. Gardner (1993). Building good business relationships-More than just partnering or strategic alliances? International Journal of Physical Distribution \& Logistics Management, 23(6), 14-26.

Cox, Andrew, Paul Ireland, Chris Lonsdale, Joe Sanderson and Glyn Watson (2001). Supply chains, markets and power: mapping buyer and supplier power regimes. London: Routledge.

Croom, Simon, Pietro Romano and Mihalis Giannakis (2000). Supply chain management: an analytical framework for critical literature review. European Journal of Purchasing \& Supply Management, 6(1), 67-83.

Dornier, Philippe-Pierre and Michel Fender (2001). La logistique globale. Enjeux, principes, exemples. Paris: Les Editions d'Organisation.

Fabbe-Costes, Nathalie and Christine Roussat (2002). Management of interfaces: how to prepare students to SCM jobs? Proceedings of the $24^{\text {th }}$ Centro Español de Logistica Conference and the $V^{\text {th }}$ International Eurolog Symposium, Barcelona, June, 1-22 (CDrom).
Fulconis, François (1999). Logistique et administration générale des structures en réseau. Gestion 2000, 16(4), 109-125.

Garets (des), Véronique (2000). Les relations distributeur-fabricant et les modalités de leur coordination. In Nathalie Fabbe-Costes, Jacques Colin and Gilles Paché (Eds.), Faire de la recherche en logistique et distribution? (pp. 109-126). Paris: Vuibert-Fnege.

Hauguel, Philippe and Eric Viardot (2001). De la supply chain au réseau industriel. L'Expansion Management Review, 101, 94100.

Jarillo, J. Carlos (1993). Strategic networks. Creating the borderless organization. Oxford: Butterworth-Heinemann.

LaLonde, Bernard J. and Terrance L. Pohlen (1996). Issues in supply chain costing. International Journal of Logistics Management, 7(1), 112.

Lambert, Douglas M. and Martha C. Cooper (2000). Issues in supply chain management. Industrial Marketing Management, 29(1), 65-83.

Lambert, Douglas M., James R. Stock and Lisa M. Ellram (1998). Fundamentals of logistics management. Burr Ridge (IL): IrwinMcGraw-Hill.

Lebraty, Jacques (2000). S'intéresser à la logistique: un pari scientifique, managérial et pédagogique. In Nathalie Fabbe-Costes, Jacques Colin and Gilles Paché (Eds.), Faire de la recherche en logistique et distribution? (pp. 5-28). Paris: Vuibert-Fnege.

Manzano-Mannarelli, Myriam (2000). Le développement de la coopération entre les institutions du canal de distribution: le cas de l'évolution de la relation entre les producteurs et les grands distributeurs français. Thèse de Doctorat en Sciences de Gestion, Paris: CNAM.

Mentzer, John T., William DeWitt, James S. Keebler, Soonhong Min, Nancy W. Nix, Carlo D. Smith and Zach G. Zacharia (2001). Defining supply chain management. Journal of Business Logistics, 22(2), 1-25. 
Miles, Raymond E. and Charles C. Snow (1995). The new network firm: a spherical structure built on a human investment philosophy. Organizational Dynamics, 23(4), 5-18.

Naylor, Ben J., Mohamed M. Naim and Danny Berry (1999). Leagility: integrating the lean and agile manufacturing paradigms in the total supply chain. International Journal of Production Economics, 62(1-2), 107-118.

Paché, Gilles (2003). Les paradoxes décisionnels du SCM: stabilité vs adaptabilité des configurations logistiques. Actes $d u 3^{e}$ Colloque de l'Association Internationale et Interdisciplinaire de la Décision, Paris, March, 1-10 (CD-rom).

Peck, Helen and Uta Jüttner (2000). Strategy and relationships: defining the interface in supply chain contexts. International Journal of Logistics Management, 11(2), 33-44.

Poirier, Charles C. and Stephen E. Reiter (1996). Supply chain optimization: building the strongest total business network, San Francisco (CA): Berrett-Koehler Publishers.

Scott, Charles and Roy Westbrook (1991). New strategic tools for supply chain management. International Journal of Physical Distribution \& Logistics Management, 21(1), 23-33.

Seuring, Stefan (2002). Cost management in supply chains-Different research approaches. In Stefan Seuring and Maria Goldbach (Eds.), Cost management in supply chains (pp. 111). Heidelberg: Physica-Verlag.

Stevens, Graham C. (1989). Integrating the supply chain. Logistics Today, 8(4), 19-22.

Tayur, Sridhar, Ram Ganeshan and Michael Magazine (1998). Quantitative models for supply chain management. Dordrecht: Kluwer Academic Publishers.

Vokurka, Robert J., Gail M. Zank and Carl M. Lund III (2002). Improving competitiveness through supply chain management: a cumulative improvement approach. Competitiveness Review, 12(1), 14-25.
François Fulconis is Assistant Professor of Strategic Management at the Université d'Avignon et des Pays de Vaucluse, France.

Gilles Paché is Professor of Logistics and Strategic Marketing at the Université Montpellier I, France.

They are both members of the Research Center on Transport and Logistics (CRET-LOG), located in Aix-en-Provence, France. 